\title{
IMR Abstracts
}

Editor-in-Chief: Robert A. Laudise • Associate Editors: Shigeyuki Sōmiya, Heinrich J. Wollenberger

\section{TABLE OF CONTENTS}

\section{COMMUNICATIONS}

A study of microstructure and ductility of directionally solidified $\mathrm{Ni}_{50} \mathbf{A l}_{\mathbf{2 0}} \mathrm{Fe}_{30}$

J. Chen, J.H. Lee, Y.T. Lee, Q. Zheng, Y. Yu, Y.A. Li, Y.J. Tang, Z.Q. Hu

Fully dense $\mathrm{Al}-\mathrm{Pb}$ nanocomposite bulk samples consolidated from mechanically milled powders

F. Zhou, H.W. Sheng, K. Lu

X7R type lead complex perovskite ferroelectric ceramics with high dielectric constant

L. Ruan, L. Li, Z. Gui

Method for producing large, stable concentrations of $\mathrm{Sc}^{2+}$ in optically clear $\mathrm{CaF}_{2}$ crystals

C.L. Marquardt, J.F. Pinto, R.E. Allen, L. Esterowit, A.Yu. Dergachev,

S. Ke, S.B. Mirov

\section{ARTICLES}

Effect of sintering temperature and cooling rate on microstructure, phase formation, and critical current density of $\mathrm{Ag}$-sheathed $\mathrm{Bi}_{1.8} \mathrm{~Pb}_{0.4} \mathrm{Sr}_{2} \mathrm{Ca}_{2} \mathrm{Cu}_{3} \mathrm{O}_{\mathrm{x}}$ superconducting tapes

J.P. Singh, N. Vasanthamohan

Trapping mode of $\mathrm{Y}_{2} \mathrm{BaCuO}_{5}$ and $\mathrm{BaCeO}_{3}$ inclusions within the melltextured $\mathrm{YBa}_{2} \mathrm{Cu}_{3} \mathrm{O}_{7-\mathrm{y}}$ crystals

C-J. Kim, K-B. Kim, I-H. Kuk, G-W. Hong

Study of microstructures of Ag-sheathed (BiPbSrCaCuO) multifilamentary tapes in various stages of processing R.K. Wang, X.H. Wang, R. Bhasale, H.K. Liu, S.X. Dou

Supercritical antisolvent precipitation: A new technique for preparing submicronic yttrium powders to improve YBCO superconductors

E. Reverchon, C. Celano, G. Della Porta, A. Di Trolio, S. Pace

First-principles investigation on environmental embrittlement of TiAl Y. Liu, K.Y. Chen, J.H. Zhang, G. Lu, Z.Q. Hu

Microstructural control of pitch matrix carbon-carbon composite by iodine treatment

H. Kajiura, Y. Tanabe, E. Yasuda, A. Kaiho, I. Shiota, S. Yamada

Investigation of $\mathrm{Al}-\mathrm{Pb}$ nanocomposites synthesized by non-equilibrium processes

H.W. Sheng, F. Zhou, Z.Q. Hu, K. Lu

The initiation of spontaneous infiltration of alloys into carbon preforms in air

X.F. Yang, X.M. Xi, L.M. Xiao
Hydrothermal preparation of the mixed titanium (IV) phosphatephenylphosphonates and characterization of their properties E. Jaimez, A.I. Bortun, S.A. Khainakov, I.I. Voitko, J.R. García, J. Rodríguez

Influence of $\mathrm{Fe}$ impurity in nitridation of $\mathrm{Si}+\mathrm{B}_{4} \mathrm{C}$ green compact D.R. Liu, M. Miyata, Y. Yasutomi, S. Shinozaki

Metallurgical reactions controlling the brazing of $\mathrm{Al}_{2} \mathrm{O}_{3}$ with $\mathrm{Ag}-\mathrm{Cu}-\mathrm{Ti}$ filler alloys

M. Paulasto, J. Kivilahti

Microstructural development of $\mathrm{Si}_{3} \mathrm{~N}_{4}-\mathrm{SiC}-\mathrm{Y}_{2} \mathrm{O}_{3}$ ceramics derived from polymeric precursors

Y. Iwamoto, K-I. Kikuta, S-I. Hirano

Reactive ion etching damage to the electrical properties of ferroelectric thin films

W. Pan, C.L. Thio, S.B. Desu

Influence of the microstructure of PT/SI substrates on textured growth of barium titanate thin films prepared by pulsed laser deposition C.S. Hwang, M.D. Vaudin, P.K. Schenck

Composition and chemical width of ultra-thin amorphous films at grain boundaries in silicon nitride

H. Gu, R.M. Cannon, M. Rühle

The dependence of structural and mechanical properties on film thickness in sol-gel zirconia films

M.J. Paterson, P.J.K. Paterson, B. Ben-Nissan

Transmission electron microscopy of worn zirconia surfaces W.M. Rainforth, R. Stevens

Characterization of polycrystalline silicon carbide films grown by atmospheric pressure chemical vapor deposition on polycrystalline silicon

C.A. Zorman, S. Roy, C-H. Wu, A.J. Fleischman, M. Mehregany

Origin of color in aerosol-derived vanadium-doped zirconia pigments P. Tartaj, C.J. Serna, J. Soria, M. Ocaña

Elastic loading and elastoplastic unloading from nanometer level indentations for modulus determinations

W.W. Gerberich, W. Yu, D. Kramer, A. Strojny, D. Bahr, E. Lilleodden, J. Nelson

Nitride formation in iron after nitrogen implantation in a nickel top layer

D.K. Inia, F.D. Tichelaar, W.M. Arnoldbik, A.M. Vredenberg,

D.0. Boerma

JMR Abstracts provides a listing of preliminary titles and abstracts tentatively scheduled to appear in the corresponding issue of Journal of Materia/s Research. Copyright 1997 by the Materials Research Society. All rights reserved. Although every effort is taken to provide accurate contents here, late schedule changes in Journal of Materials Research may result in articles being rescheduled for later issues or in the addition of late articles to an issue that may not be shown here. The Materials Research Society regrets any inconvenience that may result from late schedule, changes. ISSN: 1066-2375. 
Observations of grain boundary structure in submicrometer-grained Cu and Ni using high-resolution electron microscopy

Z. Horita, D.J. Smith, M. Nemoto, R.Z. Valiev, T.G. Langdon

Preparation of $\mathrm{LaFeO}_{3}$ particles by sol-gel technology

C. Vázquez-Vázquez, P. Kögerler, M.A. López-Quintela, R.D. Sánchez, J. Rivas

Development of preferred orientation in annealing of Fe-3.25\%Si in a high magnetic field

N. Masahashi, M. Matsuo, K. Watanabe

Noble metal silicide formation in metal/Si structures during oxygen annealing: Implications for perouskite-based memory devices K.L. Saenger, A. Grill, C. Cabral Jr.

Preparation and optical properties of nanocrystallites of $\mathrm{RE}_{2} \mathrm{Sn}_{2-x} \mathrm{~B}_{x}^{\prime} \mathrm{O}_{7}$ $\left(\mathrm{RE}=\mathrm{Sm}, \mathrm{Ce} ; \mathrm{B}^{\prime}=\mathrm{Fe}, \mathrm{Co}, \mathrm{Ni} ; 0.0 \leq \mathrm{x} \leq 1.0\right)$

X. Gong, P. Wu, W. Chen, H. Yang
A study of piezoelectric orthorhombic $\mathrm{Ta}_{2} \mathrm{O}_{5}$

B.R. Jooste, H.J. Viljoen

Practical aspects in the drawing of an optical fiber

S.R. Choudhury, Y. Jaluria

Thermal transport due to material and gas flow in a furnace for drawing an optical fiber

S.R. Choudhury, Y. Jaluria

Crystallization of ternary $\mathrm{Zr}$ based glasses-Kinetics and microstructure G.K. Dey, R.T. Savalia, E.G. Baburaj, S. Banerjee

\section{ERRATUM}

Erratum: "In situ $x$-ray investigation of hydrogen charging in thin film bimetallic electrodes" [J. Mater. Res. 8, 2091 (1997)]

N.M. Jisrawi, H. Wiesmann, M.W. Ruckman, T.R. Thurston,

G. Reisfeld, B.M. Ocko, M. Strongin

\section{ABSTRACTS}

\section{COMMUNICATIONS}

A study of microstructure and ductility of directionally solidified

$\mathrm{Ni}_{50} \mathrm{Al}_{20} \mathrm{Fe}_{30}$

J. Chen ${ }^{\star}$, J.H. Lee*, Y.T. Lee*, Q. Zheng ${ }^{+}$, Y. Yu+ ${ }^{+}$Y.A. Li ${ }^{+}$, Y.J. Tang ${ }^{+}$,

Z.Q. $\mathrm{Hu}^{+}$

("Korea Institute of Machinery and Materials, +Academia Sinica)

The microstructure and ductility of directionally solidified

$\mathrm{Ni}_{50} \mathrm{Al}_{20} \mathrm{Fe}_{30}$ were studied. Calculation and experiment show that the elastic modulus of the sample with completely eutectic lamellar structure is higher than that of the sample with dendritic structure. During deformation, in the samples with dendritic structure, some load is transferred from the pro-eutectic area to the $\gamma$-rich eutectic area and enhances the ductility of the sample. The existence of thick interdendritic $\gamma$-phase and thick lamellar $\gamma$-phase in the eutectic area of the dendritic sample is very effective to suppress the microcrack propagation and also contribute to the ductility enhancement.

Order No.: JA802-001

(C) 1997 MRS

Fully dense Al-Pb nanocomposite bulk samples consolidated from mechanically milled powders

F. Zhou, H.W. Sheng, K. Lu

(Chinese Academy of Sciences)

Powders with a nanostructured mixture of pure $\mathrm{Al}$ and $\mathrm{Pb}$ phase were produced by mechanical milling of elemental blends of $\mathrm{Al}$ and $\mathrm{Pb}$ with a composition of $\mathrm{Al}_{90} \mathrm{~Pb}_{10}$ (wt.\%). Under a pressure of $1.5 \mathrm{GPa}$ at $280^{\circ} \mathrm{C}$, the as-milled powders were successfully consolidated into bulk, full-density samples ( $>99.5 \%$ theoretical density), while the average grain sizes of Al and $\mathrm{Pb}$ in the compacted samples keep unchanged with respect to those in the as-milled powders. The achievement of the full-density without grain coarsening in the consolidation process could be reasonably attributed to melting of the nanometer-sized $\mathrm{Pb}$ particles of which the melting point is considerably depressed.

Order No.: JA802-002

(C) 1997 MRS

X7R type lead complex perovskite ferroelectric ceramics with high dielectric constant

L. Ruan, L. Li, Z. Gui

(Tsinghua University)

A new X7R type dielectric ceramics for PMN-BT-PT system with a high dielectric constant $(4832)$ and a low-firing temperature $\left(1100-1130^{\circ} \mathrm{C}\right)$ were prepared by a mixed-sintering method. The results of XRD, SEM,
EDAX and dielectric measurements showed that the dielectric ceramics is a two-phase composite with the high dielectric constant originating from the ferroelectric relaxor, and the temperature stability of the dielectric properties from two-phase coexistence.

Order No.: JA802-003

(C) 1997 MRS

Method for producing large, stable concentrations of $\mathrm{Sc}^{2+}$ in optically clear $\mathrm{CaF}_{2}$ crystals

C.L. Marquardt, J.F. Pinto, R.E. Allen, L. Esterowitz, A.Yu. Dergachev, S. Ke, S.B. Mirov

(Naval Research Laboratory)

This communication describes a new method for producing stable, high concentrations of $\mathrm{Sc}^{2+}$ in optically clear $\mathrm{CaF}_{2}$ crystals. We have achieved $\mathrm{Sc}^{2+}$ concentrations as high as $3 \times 10^{18} \mathrm{~cm}^{-3}$ without degradation of optical quality. We have converted as much as $5 \%$ of the scandium dopant to the divalent state. The concentration of divalent scandium is stable during room temperature storage for periods of at least one year. Order No.: JA802-004

(C) 1997 MRS

\section{ARTICLES}

Effect of sintering temperature and cooling rate on microstructure, phase formation, and critical current density of $\mathrm{Ag}$-sheathed $\mathrm{Bi}_{1.8} \mathrm{~Pb}_{0.4} \mathrm{Sr}_{2} \mathrm{Ca}_{2} \mathrm{Cu}_{3} \mathrm{O}_{\mathrm{x}}$ superconducting tapes

J.P. Singh, N. Vasanthamohan

(Argonne National Laboratory)

Silver-sheathed $\mathrm{Bi}-\mathrm{Pb}-\mathrm{Sr}-\mathrm{Ca}-\mathrm{Cu}-\mathrm{O}$ (2223) superconducting tapes (with a starting composition of $\mathrm{Bi}_{1.8} \mathrm{~Pb}_{0.4} \mathrm{Sr}_{2} \mathrm{Ca}_{1} \mathrm{Cu}_{2} \mathrm{O}_{8}$, calcium cuprate and $\mathrm{CuO}$ ) were fabricated by the powder-in-tube technique. The tapes were sintered at various temperatures to optimize the formation of $\mathrm{Bi}_{1.8} \mathrm{~Pb}_{0.4} \mathrm{Sr}_{2} \mathrm{Ca}_{2} \mathrm{Cu}_{3} \mathrm{O}_{10}$ phase within the tape. The results show that sintering within the temperature range of $815-825^{\circ} \mathrm{C}$ can produce tapes with high critical current density $\left(\mathrm{J}_{\mathrm{c}}\right)$. The $\mathrm{J}_{\mathrm{c}}$ of samples sintered at the higher temperature of $825^{\circ} \mathrm{C}$, where more liquid is present, depended markedly on the rate at which tapes were cooled from the sintering temperature; samples sintered at lower temperatures did not exhibit such a cooling-rate effect. The optimum combination of phase purity and microstructure that yielded an average transport $J_{c}$ of $\geq 2.5 \times 10^{4} \mathrm{~A} / \mathrm{cm}^{2}$ was obtained when the tapes were sintered at $825^{\circ} \mathrm{C}$ for $150 \mathrm{~h}$ and cooled at a rate of $25^{\circ} \mathrm{C} / \mathrm{h}$ from the sintering temperature. Quenching studies indicate that the Bi-2223 phase becomes unstable below $700^{\circ} \mathrm{C}$ during slow cooling. This result may have important implications for processing Bi-Sr-Ca-Cu-0 tapes with high 
$J_{c}$. Addition of $15 \mathrm{vol} . \% \mathrm{Ag}$ flakes to the monolithic core exerted no significant effect on $J_{\text {. }}$

Order No: JA802-005

(C) 1997 MRS

Trapping mode of $\mathrm{Y}_{2} \mathrm{BaCuO}_{5}$ and $\mathrm{BaCeO}_{3}$ inclusions within the melttextured $\mathrm{YBa}_{2} \mathrm{Cu}_{3} \mathrm{O}_{7-\mathrm{y}}$ erystals

C-J. Kim, K-B. Kim, l-H. Kuk, G-W. Hong

(Korea Atomic Energy Research Institute)

Particle segregation mode of two different inclusion phases of $\mathrm{Y}_{2} \mathrm{BaCuO}_{5}$ (Y211: a dissolving phase in a Ba-Cu-O liquid phase) and $\mathrm{BaCeO}_{3}$ (a non-dissolving phase) was investigated in the melt-textured $\mathrm{YBa}_{2} \mathrm{Cu}_{3} \mathrm{O}_{7-y}$ (Y123) with $\mathrm{BaCeO}_{3}$ addition (0-20 wt.\%), and with $30 \mathrm{wt} \%$ Y211 plus $\mathrm{BaCeO}_{3}(0-20 \mathrm{wt}$.\%). The segregation mode of the inclusion phases is dependent not only on the type of the inclusion phases but also their amounts. When the trapped amount of the Y211 is small, they make an $x$-like pattern on the diagonal planes of the $Y 123$ crystal. When the amount of the Y211 is large, meanwhile, the Y211 particles are trapped within four tetrahedral spaces (normal to the c-axis) bounded by the diagonal planes of the Y123 crystal, with no Y211 trapping within two tetrahedral spaces parallel. On the other hand, the non-dissolving $\mathrm{BaCeO}_{3}$ particles make linear tracks normal to the $\{100\}$ growth fronts of the $\mathrm{Y} 123$ crystal.

Order No.: JAB02-006

C) 1997 MRS

\section{Study of microstructures of Ag-sheathed (BiPbSrCaCuO)}

multifilamentary tapes in various stages of processing

R.K. Wang*, X.H. Wang*, R. Bhasale+, H.K. Liu+, S.X. Dou+

("General Institute of Non-Ferrous Metals, +University of Wollongong)

Microstructures of 27-filament $\left(\mathrm{Bi}, \mathrm{Pb}_{2} \mathrm{Sr}_{2} \mathrm{Ca}_{2} \mathrm{Cu}_{3} \mathrm{O}_{10+\times}\right.$ (BPSCCO

2223) tape at various stages of repetitive rolling and sintering have been investigated using TEM and SEM. It was found that the dislocation density increases with increasing sintering time with the maximum dislocation density of $10^{12} / \mathrm{cm}^{2}$ achieved for tapes sintered for $220 \mathrm{~h}$. The interface between $\mathrm{Ag}$-sheath and oxide core was observed to be wave-like. Small irregular 2223 colonies and cracks in the oxide cores were often observed near the Ag-sheath/oxide core interface. Repetitively rolled and sintered specimen with a total sintering time of $220 \mathrm{~h}$ was observed to have optimum phase purity of 2223 phase. Prolonged sintering results in recrystallization of the 2223 grains, degrading the texture of the oxide core.

Order No.: JA802-007

(C) 1997 MRS

\section{Supercritical antisolvent precipitation: A new technique for preparing} submicronic yttrium powders to improve YBCO superconductors E. Reverchon, C. Celano, G. Della Porta, A. Di Trolio, S. Pace (Università di Salerno)

The solvent, supercritical antisolvent technique (SAS) has been used to produce submicronic particles of yttrium acetate for the synthesis of YBCO superconductors. For this purpose, in a continuous SAS apparatus dimethylsulfoxide (DMSO) as ytrium acetate solvent and supercritical carbon dioxide as antisolvent have been adopted. Experiments have been performed in the pressure range between 70 and 160 bar and for temperatures between 40 and $70^{\circ} \mathrm{C}$. Different concentrations of yttrium acetate in DMSO have also been tested. Various morphologies of ytrium acetate particles have been obtained, having mean particle diameters from 0.1 to $7 \mathrm{~mm}$. At $40^{\circ} \mathrm{C}$ and pressures larger than 120 bar, submicronic spherical particles of yttrium acetate of about $0.1 \mu \mathrm{m}$ diameter and with a narrow particle size distribution have been achieved.

Order No.: JAB02-008

(C) 1997 MRS

First-principles investigation on environmental embrittlement of TiAJ Y. Liu, K.Y. Chen, J.H. Zhang, G. Lu, Z.Q. Hu

(Academia Sinica)

To investigate the hydrogen embrittlement and Mn ductilization effects in TiAl, the electronic structures of pure, H-doped, Mn-doped, and $\mathrm{Mn}, \mathrm{H}$-codoped TiAl have been studied by the first-principles discrete variational $X_{\alpha}$ calculations. Local environmental total bond order (LTBO), which is developed for the description of the cohesive properties in a local atom environment involving impurities, should be regarded as a new microscopic criterion for embrittlement. The larger LTBO presents the stronger cohesion and the better ductility of the system. Our results show that $H$ obviously decreases LTBO while $\mathrm{Mn}$ increases it, which suggests $H$ is an embrittler while $\mathrm{Mn}$ is a ductilizer. It is of key importance to understand hydrogen embrittlement: that hydrogen causes the weakening of its surrounding metal-metal bonds.

Order No.: JA802-009

(c) 1997 MRS

Microstructural control of pitch matrix carbon-carbon composite by lodine treatment

H. Kajiura*, Y. Tanabe*, E. Yasuda*, A. Kaiho+, I. Shiota ${ }^{+}$S. Yamada ${ }^{*}$ ("Tokyo Institute of Technology, + Kogakuin University, "Teikyo University of Science and Technology)

Matrix microstructure of a pitch based carbon-carbon composite was controlled by an iodine treatment. Coal-tar pitch having the softening point of $101^{\circ} \mathrm{C}$ was used as a matrix precursor. The iodine treatment was carried out on a pitch impregnated specimen at $90^{\circ} \mathrm{C}$ for $3-20$ hours. The specimen was carbonized at $800^{\circ} \mathrm{C}$ and graphitized at $2000-3000^{\circ} \mathrm{C}$. The carbon yield increased from $73 \%$ to $93 \%$ by the iodine treatment. Microstructures of carbonized specimens changed from a flow type texture to a mosaic type one by the iodine treatment. The microstructural development to graphitic structure was suppressed by the iodine treatment.

Order No.: JAB02-010

(C) 1997 MRS

Investigation of Al-Pb nanocomposites synthesized by non-equilibrium processes

H.W. Sheng, F. Zhou, Z.Q. Hu, K. Lu

(Chinese Academy of Sciences)

Two non-equilibrium processes (melt-spinning and ball-milling) were successfully employed to synthesize $\mathrm{Al}_{1-x} \mathrm{~Pb}_{x}(\mathrm{x}=5,10,20,30 \mathrm{wt} . \%)$ nanocomposites with distinct microstructures. In the melt-spun (MS) $\mathrm{Al}-\mathrm{Pb}$ alloys, the nanometer-sized $\mathrm{Pb}$ particles are uniformly distributed in the micrometer-grained Al matrix and have an orientational relationship with the matrix, while in the ball-milled (BM) samples, both $\mathrm{Pb}$ and $\mathrm{Al}$ components are refined with prolonged milling time, forming nanocomposites with $\mathrm{Pb}$ particles homogeneously dispersed into the Al matrix. The minimum particle size of $\mathrm{Pb}$ in the milled samples linearly increases with the $\mathrm{Pb}$ content. The microhardness of the BM Al-Pb samples is much larger than that of the MS samples, which mainly results from strengthening effects of the nanometer scale Al grains following the Hall-Petch relationship. The microhardness for both $\mathrm{BM}$ and $\mathrm{MS} \mathrm{Al}-\mathrm{Pb}$ samples varies with the $\mathrm{Pb}$ content, and maximum hardness for both samples exists when $\mathrm{Pb}$ content is about $5 \mathrm{wt} . \%$, indicating that small amounts of $\mathrm{Pb}$, in the form of nanoparticles, may strengthen the Al matrix.

Order No.: JA802-011

(C) 1997 MRS

\section{The initiation of spontaneous infiltration of alloys into carbon preforms in air} X.F. Yang, X.M. Xi, L.M. Xiao

(Auburn University)

It was found in a previous work that Al-Si alloy could spontaneously infiltrate into carbon preforms in air. In this study, the initiation stage of the infiltration process was investigated in detail through two different infiltration experiments. In one experiment, carbon preforms were fully dipped into an alloy bath that was exposed to air, and in the other experiment a carbon preform was only partially dipped into an alloy bath that was protected with a flowing Ar or $\mathrm{N}_{2}$ gas. Experimental results have suggested that the initiation of infiltration is controlled by the pressure of oxidizing gases such as $\mathrm{O}_{2}$ or $\mathrm{CO}$ at the infiltration tront and is not affected by the presence or absence of $\mathrm{N}_{2}$ gas. The critical pressure of oxidizing gases is estimated to be on the order of $10^{-4} \mathrm{~atm}$ for systems investigated in our experiments. An effective way to reduce the $\mathrm{O}_{2}$ or $\mathrm{CO}$ pressure is to flush a preform with non-oxidizing gases during or before infiltration, or to use an active metal to reduce the $\mathrm{O}_{2}$ pressure and thus the corresponding $\mathrm{CO}$ pressure.

Order No.: JA802-012

(C) 1997 MRS 
Hydrothermal preparation of the mixed titanium (IV) phosphatephenyiphosphonates and characterization of their properties E. Jaimez*, A.I. Bortun*, S.A. Khainakov*, I.I. Voitko+, J.R. Garcia*, J. Rodríguez*

( Universidad de Oviedo, +Kiev State Trade and Economic University) Mixed crystalline titanium (IV) phosphate-phenylphosphonates were synthesized under hydrothermal conditions using tetramethylammonium hydroxide as a templating reagent. It was found that at a relatively low molar ratio $\mathrm{H}_{3} \mathrm{PO}_{4}: \mathrm{PhPO}_{3} \mathrm{H}_{2}$ in the reaction mixture $(<1)$ only a pure $\alpha-$ titanium phenylphosphonate is formed. At the molar ratio $\mathrm{H}_{3} \mathrm{PO}_{4}: \mathrm{PhPO}_{3} \mathrm{H}_{2}$ $=(3-5): 1$ the formation of a novel mixed compound titanium (IV) dihydrogenphosphate-hydrogenphosphate-phenylphosphonate takes place. Further increase of the ratio $\mathrm{H}_{3} \mathrm{PO}_{4}: \mathrm{PhPO}_{3} \mathrm{H}_{2}$ gives mechanical mixtures of different phases. Preliminary results on the characterization of the novel compound of formula Ti( $\left(\mathrm{H}_{2} \mathrm{PO}_{4}\right)_{1.25}\left(\mathrm{HPO}_{4}\right)_{0.12}\left(\mathrm{C}_{6} \mathrm{H}_{5} \mathrm{PO}_{3}\right)_{1.25} \cdot 0.3 \mathrm{H}_{2} \mathrm{O}$ are presented. Order No.: JA802-013

C) 1997 MRS

\section{Influence of $\mathrm{Fe}$ impurity in nitridation of $\mathrm{Si}_{+}+\mathrm{B}_{4} \mathrm{C}$ green compact}

[.R. Liu*, M. Miyata ${ }^{+}$, Y. Yasutomi+, S. Shinozaki*

(Ford Motor Company, +Hitachi Ltd.)

The addition of the $\mathrm{B}_{4} \mathrm{C}$ powder retarded the nitridation of the silicon powder green body by the formation of a borosilicate layer in interfaces between Si grains. The viscous layers hindered the SiO formation and the $\mathrm{Si}$ and $\mathrm{N}$ diffusion. Despite the presence of borosilicate layers, the Fe impurity in the green body still promoted the Si nitridation process by the formation of the fluid iron silicide and the promotion of the $\mathrm{B}_{4} \mathrm{C}$ conversion to $\mathrm{BN}$ in gaps or holes in the viscous borosilicate layers. The addition of $5 \%$ $\mathrm{H}_{2}$ in the $\mathrm{N}_{2}$ atmusphere accelerated the $\mathrm{Si}+\mathrm{B}_{4} \mathrm{C}$ nitridation, where the hydrogen acted as an oxygen getter, thus reducing the amount of glassy borosilicate in the interface.

Order No.: JA802-014

CC 1997 MRS

\section{Metallurgical reactions controlling the brazing of $\mathrm{Al}_{2} \mathrm{O}_{3}$ with $\mathrm{Ag}$-Cu-Ti} filler alloys

M. Paulasto, J. Kivilahti

(He/sinkı University of Technology)

Metallurgical reactions controlling the Ti-activation in brazing of $\mathrm{Al}_{2} \mathrm{O}_{3}$ have been studied by means of microstructural and thermodynamic analysis. The reactions of titanium with oxygen and copper are shown to be decisive in active brazing. The miscibility gap in the $\mathrm{Ag}$ - $\mathrm{Cu}$-Ti system divides the liquid braze into $\mathrm{Ag}$-rich (L1) and TiCu-rich (L2) liquids. The liquid $\mathrm{L} 2$ reacts with alumina forming the mixed oxide $(\mathrm{Ti}, \mathrm{Al})_{4} \mathrm{Cu}_{2} \mathrm{O}$. In addition to alumina, Ti reacts with the oxygen that the filler alloys usually contain and forms a brittle ribbon composed of Ti, $\mathrm{O}$ and Ti-Cu-O phases in the braze. The formation of Ti-oxides next to the alumina is possible only in the filler alloys of highest $\mathrm{Ag}$-content.

Order No.: JA802-015

(C) 1997 MRS

\section{Microstructural development of $\mathrm{Si}_{3} \mathrm{~N}_{4}-\mathrm{SiC}-\mathrm{Y}_{2} \mathrm{O}_{3}$ ceramics derived} from polymeric precursors

Y. Iwamoto* ${ }^{*}$ K-I. Kikuta ${ }^{+}$, S-I. Hirano ${ }^{\#}$

("Synergy Ceramics Laboratory, +National Industrial Research Institute of Nagoya, "Nagoya University)

[Si-Y-O-C-N] amorphous powders were synthesized by the pyrolysis at $1000^{\circ} \mathrm{C}$ in $\mathrm{N}_{2}$ of chemically modified perhydropolysilazane using n-decyl alcohol and yttrium tri-methoxide. [Si-Y-O-C-N] amorphous powders yielded a unique fibrous microstructure by heat treatment in $\mathrm{N}_{2}$ at $1800^{\circ} \mathrm{C}$. The fibrous microstructure was composed of $\beta$-Si ${ }_{3} \mathrm{~N}_{4}$ whiskers with submicron in diameter and more than $10 \mu \mathrm{m}$ in length. Fully dense $\mathrm{Si}_{3} \mathrm{~N}_{4}-\mathrm{SiC}-\mathrm{Y}_{2} \mathrm{O}_{3}$ ceramics were also fabricated by heat treatment at $1800^{\circ} \mathrm{C}$ followed by powder-vehicle hot pressing at $1700^{\circ} \mathrm{C}$. After these two-step processings, [Si-Y-0-C-N] amorphous powders yielded a unique fine-grained microstructure composed of submicron grains with high aspect ratio. Order No.: JA802-016
Reactive ion etching damage to the electrical properties of ferroelectric thin films

W. Pan, C.L. Thio, S.B. Desu

(Virginia Polytechnic Institute and State University)

Reactive ion etching damage to $\mathrm{Pt} / \mathrm{Pb}(\mathrm{Zr}, \mathrm{Ti}) \mathrm{O}_{3} / \mathrm{Pt}$ ferroelectric capacitors was evaluated under Ar bombardment and $\mathrm{CHCIFCF}_{3}$ etch plasmas. The hysteresis and degradation properties including fatigue and leakage current were examined systematically to study the mechanism of damage. The damage was measured quantitatively by comparing the relative voltage shift with respect to the initial hysteresis loops. The damage effects were found to be dependent on etching time and mainly due to the physical effect of ion bombardment. The electrical properties of the etched $\mathrm{Pt} / \mathrm{Pb}(\mathrm{Zr}, \mathrm{Ti}) \mathrm{O}_{3} / \mathrm{Pt}$ capacitors were substantially recovered by annealing at $400^{\circ} \mathrm{C}$ for $30 \mathrm{~min}$.

Order No.: JA802-017

(C) 1997 MRS

Influence of the microstructure of PT/SI substrates on textured growth of barium titanate thin films prepared by pulsed laser deposition

C.S. Hwang, M.D. Vaudin, P.K. Schenck (National Institute of Standards and Technology)

Pt-coated silicon substrates with strong (111) Pt texture were annealed in an oxidizing atmosphere at temperatures from $500^{\circ} \mathrm{C}$ to $750^{\circ} \mathrm{C}$. $\mathrm{BaTiO}_{3}$ thin films were deposited by pulsed laser ablation on the substrates. Observation by transmission electron microscopy showed that the substrate anneal caused the formation of $\mathrm{TiO}_{2}$ in the Pt layer, accompanied by the formation of a high density of faceted protrusions on the Pt surface, particularly at the higher anneal temperatures. The Pt protrusions had (111) facets, parallel to the substrate surface, on which (100)-oriented $\mathrm{BaTiO}_{3}$ grains were observed. $\mathrm{BaTiO}_{3}$ grains with an epitaxial relationship to the Pt lattice were observed on inclined facets of the Pt protrusions [which were not (111) planes], and also on the non-planar regions of the Pt surface. These epitaxial $\mathrm{BaTiO}_{3}$ grains had (111) preferred orientation relative to the substrate surface. Thus, the $\mathrm{BaTiO}_{3}$ films displayed bimodal growth behavior, with both $(100)$ texture and (111) epitaxy. We propose a model for this behavior based on surface energy considerations.

Order No.: JA802-018

(C) 1997 MRS

Composition and chemical width of ultra-thin amorphous films at grain boundaries in silicon nitride

H. Gu* , R.M. Cannon ${ }^{*}$, M. Rühle ${ }^{+}$

('Japan Science and Technology Corporation, +Max Planck Institut für Metallforschung, " Lawrence Berkeley Laboratory-University of CaliforniaBerkeley)

Two different electron energy loss spectroscopy (EELS) quantitative analytical methods for obtaining complete compositions from interface regions are applied to ultra-thin oxide-based amorphous grain boundary (GB) films of $\sim 1 \mathrm{~nm}$ thickness in high-purity $\mathrm{HIPed} \mathrm{Si}_{3} \mathrm{~N}_{4}$ ceramics. The first method, $l$, is a quantification of the segregation excess at interfaces for all the elements, including the bulk constituents such as silicon and nitrogen; this yields a GB film composition of $\mathrm{SiN}_{0.49 \pm 1.4} 0_{1.02 \pm 0.42}$ when combined with the average film thickness from high resolution electron microscopy (HREM). The second method, II, is based on an EELS nearedge structure (ELNES) analysis of the $\mathrm{Si}-L_{23}$ edge of thin GB films which permits a subtraction procedure that yields a complete EELS spectrum, e.g., that also includes the $0-K$ and $N-K$ edges, explicitly for the $G B$ film. From analysis of these spectra, the film composition is directly obtained as $\mathrm{SiN}_{0.63 \pm 0.19} \mathrm{O}_{1.44 \pm 0.33}$, close to the one obtained by the first method but with much better statistical quality. The improved quality results from the fewer assumptions made in method II, while in method I uniform thickness and illumination condition have to be assumed, and correction of such effects yields an extra systematic error. Method II is convenient as it does not depend on the film thickness detected by HREM, nor suffer from material lost by preferential thinning at the GB. In addition, a chemical width for these films can be deduced as $1.33 \pm 0.25 \mathrm{~nm}$, which depends on an estimation of film density based on its composition. Such a chemical width is 
in good agreement with the structural thickness determined by HREM, with a small difference that is probably due to the different way in which these techniques probe the GB film. The GB film compositions are both nonstoichiometric but in an opposite sense; this discrepancy is probably due to different ways of treating the surface oxidation layers in both methods. Order No.: JA802-019

(C) 1997 MRS

The dependence of structural and mechanical properties on film thickness in sol-gel zirconia films

M.J. Paterson*, P.J.K. Paterson+, B. Ben-Nissan ${ }^{\#}$

('Macquarie University, ${ }^{+}$Royal Melbourne Institute of Technology,

"University of Technology)

The structure, morphology and mechanical properties of sol-gel zirconia films have been examined using XRD, AES depth profiling, AFM and ultramicro-indentation. There is a systematic variation in the structure and morphology of the zirconia films with increasing thickness. These changes include increases in the amount of monoclinic phase, substrate oxides, and a decrease in grain size. Ultramicro-indentation measurements indicate measured hardness increases with film thickness. The highest hardness value was $6.12 \mathrm{GPa}$ for a $900 \mathrm{~nm}$ thick film. However, these values may be influenced by the substrate oxide layer at the film/substrate interface which increases with film thickness. The modulus of the films appears to be thickness independent. As the films are made up of a number of separately fired layers, it appears that the property changes observed are also related to the number of thermal cycles experienced by the sample.

Order No.: JA802-020

(C) 1997 MRS

\section{Transmission electron microscopy of worn zirconia surfaces}

W.M. Rainforth*, R. Stevens ${ }^{+}$

('University of Sheffield, +University of Bath)

The dry sliding wear behavior of a $3 \mathrm{~mol} \%$ tetragonal zirconia polycrystal (3Y-TZP) and a composite containing 20 vol. $\%$ SiC whiskers have been examined by transmission electron microscopy. High wear rates for the TZP were associated with dramatic microstructural changes. The extreme outer $\sim 400 \mathrm{~nm}$ consisted of an amorphous surface layer containing both alumina and zirconia. Below this, the $\mathrm{t}-\mathrm{ZrO}_{2}$ grain size was an order of magnitude smaller than in the starting material. At a depth of 1-2 $\mu \mathrm{m}$ the tetragonal grains had become elongated, with a maximum aspect ratio of 30:1. The first monoclinic zirconia was found at a depth of $5 \mu \mathrm{m}$. In contrast, the composite exhibited a wear rate 5 orders of magnitude lower, associated with minor microstructural changes.

Order No.: JA802-021

(C) 1997 MRS

Characterization of polycrystalline silicon carbide films grown by atmospheric pressure chemical vapor deposition on polycrystalline silicon

C.A. Zorman, S. Roy, C-H. Wu, A.J. Fleischman, M. Mehregany

(Case Western Reserve University)

$X$-ray diffraction, transmission electron microscopy, and Rutherford backscattering spectroscopy were used to characterize the microstructure of polycrystalline SiC films grown on as-deposited and annealed polysilicon substrates. For both substrate types, the texture of the $\mathrm{SiC}$ films resembles the polysilicon at the onset of $\mathrm{SiC}$ growth. During the high temperature deposition process, the as-deposited polysilicon recrystallizes without influencing the crystallinity of the overlying SiC. An investigation of the $\mathrm{SiC} /$ polysilicon interface reveals that a heteroepitaxial relationship exists between polysilicon and SiC grains. From this study, a method to control the orientation of highly textured polycrystalline $\mathrm{SiC}$ films has been developed.

Order No.: JABO2-022

C) 1997 MRS

Origin of color in aerosol-derived vanadium-doped zirconia pigments P. Tartaj ${ }^{\star}$, C.J. Serna* ${ }^{\star}$ J. Soria* ${ }^{\star}$, M. Ocaña ${ }^{+}$

('C.S.I.C., +C.S.I.C-UNSE)

The preparation of vanadium-zirconia yellow pigments from amorphous spherical $\mathrm{V}-\mathrm{ZrO}_{2}$ particles obtained by the hydrolysis of liquid aerosols consisting of a mixture of vanadium (V) oxychloride and zirconium n-propoxide is reported. The composition of the amorphous precursors (V/Zr ratio) and the heating temperature were systematically varied to determine their influence on the optical properties of the pigments. The origin of the pigments' yellow color was found to be mainly due to the presence of $\mathrm{V}_{2} \mathrm{O}_{5}$ in the outer layers of the zirconia grains. A small fraction $(\sim 15 \%)$ of the total vanadium content was found as vanadium (IV) forming a solid solution with the monoclinic zirconia lattice.

Order No.: JA802-023

(C) 1997 MRS

Elastic loading and elastoplastic unloading from nanometer level indentations for modulus determinations

W.W. Gerberich, W. Yu, D. Kramer, A. Strojny, D. Bahr, E. Lilleodden, J. Nelson

(University of Minnesota)

A new method for evaluating modulus and hardness from nanoindentation load/displacement curves is presented. As a spherical indenter penetrates an elastoplastic half-space, the elastic displacement above the contact line is presumed to diminish in proportion to the total elastic displacement under the indenter. Applying boundary conditions on the elastic and plastic displacements for elastic and rigid plastic contacts leads to an expression that can be best fit to the entire unloading curve to determine $E^{\star}$, the reduced modulus. Justification of the formulation is presented, followed by the results of a preliminary survey conducted on three predominantly isotropic materials: fused quartz, polycrystalline Al, and single crystal $W$. Diamond tips with radii ranging from $130 \mathrm{~nm}$ to $5 \mu \mathrm{m}$ were used in combination with three different nanoindentation devices. Results indicate that the method gives property values consistent with accepted values for modulus and hardness. The importance of surface roughness and indentation depth are also considered.

Order No.: JA802-024

(C) 1997 MRS

\section{Nitride formation in iron after nitrogen implantation in a nickel} top layer

D.K. Inia*, F.D. Tichelaar ${ }^{+}$, W.M. Arnoldbik* , A.M. Vredenberg*,

D.0. Boerma*\#

${ }^{*}$ Debye Institute, + Delft University of Technology, ${ }^{\sharp}$ Groningen University) Nitrogen was introduced in an iron layer underneath a top layer of nickel. This was done by ion implantation of $\mathrm{N}$ into the Ni layer at a temperature of $200^{\circ} \mathrm{C}$. During implantation and subsequent anneals at 250 and $300^{\circ} \mathrm{C}, \mathrm{N}$ diffuses from the Ni layer into the Fe layer because of a larger affinity of $\mathrm{Fe}$ for $\mathrm{N}$ than of $\mathrm{Ni}$ for $\mathrm{N}$. The concentration depth profiles of $\mathrm{N}$ in the Ni/Fe bilayers, as recorded with the nuclear reaction analysis technique, show at the highest implantation dose a peak below the Ni/Fe interface. From structural analysis techniques (x-ray diffraction and cross-sectional transmission electron microscopy) it was observed that this peak is due to the presence of an $\varepsilon-\mathrm{Fe}_{3-\mathrm{x}} \mathrm{N}$ layer below the Ni/Fe interface. It is thus shown that $\varepsilon$-nitride can be formed in Fe at such low temperatures in the absence of radiation damage.

Order No.: JA802-025

(C) 1997 MRS

Observations of grain boundary structure in submicrometer-grained $\mathrm{Cu}$ and Ni using high-resolution electron microscopy Z. Horita*, D.J. Smith+, M. Nemoto*, R.Z. Valiev"\#, T.G. Langdon§ ("Kyushu University, +Arizona State University, "Ufa State Aviation Technical University, \&University of Southern California-Los Angeles)

Submicrometer-grained (SMG) structures were produced in Cu and $\mathrm{Ni}$ using an intense plastic straining technique and the grain boundaries and their vicinities were observed by high resolution electron microscopy. The grain boundaries exhibited zigzag configurations with irregular arrangements of facets and steps and thus they were found to be in a high-energy non-equilibrium state. A similar conclusion was reached earlier for SMG Al-Mg solid solution alloys which have much lower melting points than $\mathrm{Cu}$ and $\mathrm{Ni}$, suggesting that non-equilibrium grain boundaries are a typical feature of metals processed by intense plastic straining. Order No.: JA802-026

(c) 1997MRS 
Preparation of $\mathrm{LaFeO}_{3}$ particles by sol-gel technology

C. Vázquez-Vázquez, P. Kögerler, M.A. López-Quintela, R.D. Sánchez, J. Rivas

(University of Santiago de Compostela)

The study of submicroscopic particles in already known systems has resulted in a renewed interest due to the large differences found in their properties when the particle size is reduced, and because of possible new technological applications. In this work we report the preparation of $\mathrm{LaFeO}_{3}$ particles by the sol-gel route, starting from a solution of the corresponding metallic nitrates and using urea as gelificant agent. Gels were decomposed at $200^{\circ} \mathrm{C}$ and calcined 3 hours at several temperatures, $\mathrm{T}$, in the range $250-1000^{\circ} \mathrm{C}$. The samples were structurally characterized by $x$-ray diffraction (XRD) showing that the orthoferrite crystallizes at $T$ as low as $315^{\circ} \mathrm{C}$. From the $x$-ray diffraction peak-broadening, the particle size was determined. The size increases from 60 to $300 \mathrm{~nm}$ as the calcination T increases. Infrared spectroscopy was used to characterize gels and calcined samples. From these studies a mechanism for the gel formation is proposed. The study of the magnetic properties of $\mathrm{LaFeO}_{3}$ particles show the presence of a ferromagnetic component which diminishes as the calcination temperature increases, vanishing at $\mathrm{T}=1000^{\circ} \mathrm{C}$.

Order No.: JA802-027

(C) 1997 MRS

Development of preferred orientation in annealing of $\mathrm{Fe}-3.25 \% \mathrm{Si}$ in a high magnetic field

N. Masahashi*, M. Matsuo ${ }^{+}$, K. Watanabe ${ }^{\sharp}$

("Nippon Steel Corporation, + Japan Technical Information Service,

"Tohoku University)

Annealing of a cold-rolled Fe-3.25\%Si sheet having $\{111\}<112>$ preferred orientation is performed in a high magnetic field in order to control microstructure orientation. Magnetic field (10 tesla) was applied in a direction parallel to the rolling direction. Distributions of orientation and misorientation of primary recrystallization grains in the magnetically annealed specimens are characterized with electron backscattering pattern analysis. Magnetic annealing is found to enhance the selection of $<001\rangle$ axis alignment parallel to the rolling direction in the $\{\mathrm{hk} 0\}<001>$ recrystallization texture and to favor the occurrence of low energy grain boundaries in the recrystallized microstructure. The high frequency of low angle grain boundaries results in appearance of coarse grains with traces of faint prior grain boundaries, suggesting extensive operation of the mechanism of grain coalescence. As a cause of selective formation of $\langle 100\rangle$ grains in recrystallization, magnetostriction induced by applying a magnetic field is suggested. Order No.: JA802-028

(C) 1997 MRS

Noble metal silicide formation in metal/Si structures during oxygen annealing: Implications for perovskite-based memory devices

K.L. Saenger, A. Grill, C. Cabral Jr.

(IBM T.J. Watson Research Center)

This paper investigates the potentially undesirable noble metal silicide formation reactions that may occur in noble metal electrodes deposited directly on silicon without an intervening diffusion barrier. Metal (90$100 \mathrm{~nm}) / \mathrm{Si}$ structures of $\mathrm{Pt} / \mathrm{Si}, \mathrm{Rh} / \mathrm{Si}, \mathrm{Ir} / \mathrm{Si}$, and $\mathrm{Ir} / \mathrm{Ti} / \mathrm{Si}$ were annealed in oxygen or nitrogen ambients at temperatures of $640-700^{\circ} \mathrm{C}$. Metal/silicon reactions and phase formation were studied by Rutherford backscattering spectroscopy, x-ray diffraction, and electrical resistance measurements. While complete silicidation was observed in the $\mathrm{Rh} / \mathrm{Si}$, Pt/Si, and Ir/Si samples after $640^{\circ} \mathrm{C} / 6$ min anneals in nitrogen, some Pt and most of the Ir remained after equivalent anneals in oxygen. More detailed studies of the $\mathrm{Ir} / \mathrm{Si}$ samples indicated that some Ir is left unsilicided even after a $700^{\circ} \mathrm{C} /$ 6 min anneal in $\mathrm{O}_{2}$, and that the iridium silicide formed is the semiconducting $\mid r \mathrm{Si}_{1.75}$. The formation of this silicide can be delayed, but not prevented, with the use of a $5 \mathrm{~nm}$ Ti adhesion layer between the $\mathrm{Ir}$ and $\mathrm{Si}$.

Order No.: JA802-029

(C) 1997 MRS

Preparation and optical properties of nanocrystallites of $\mathrm{RE}_{2} \mathrm{Sn}_{2-x} \mathrm{~B}_{x} \mathrm{O}_{7}$ (RE = Sm, Ce; B' = Fe, Co, Ni; $0.0 \leq x \leq 1.0)$

X. Gong*, P. Wu*, W. Chen ${ }^{*}$, H. Yang ${ }^{+}$

("Nankai University, +Tianjin University)

New pyrochlore-type rare-earth-complex oxides of nanometer size and with $\mathrm{B}$-site dopants, $\mathrm{RE}_{2} \mathrm{Sn}_{2-x} \mathrm{~B}_{\times}^{\prime} \mathrm{O}_{7}\left(\mathrm{RE}=\mathrm{Sm}, \mathrm{Ce} ; \mathrm{B}^{\prime}=\mathrm{Fe}, \mathrm{Co}, \mathrm{Ni}\right.$;
$0.0 \leq x \leq 1.0$, have been prepared by the non-alcoholate sol-gel method. The range of average particle size is from 25 to $30 \mathrm{~nm}$. It is found that this method can lower the reaction temperature (about $500 \mathrm{~K}$ ) and shorten the reaction time. The crystal structures of these nanocrystallites belong to the cubic system, and their lattice parameters are linearly related to the content of the dopant ions. The IR spectra of these nanocrystallites were investigated, and the excitation and emission spectra for these systems show that the luminescent intensities of $\mathrm{RE}^{3+}$ become weaker with the iron-group dopant in the order of $\mathrm{Fe}, \mathrm{Co}$, and $\mathrm{Ni}$.

Order No.: JA802-030

(C) 1997 MRS

A study of piezoelectric orthorhombic $\mathrm{Ta}_{2} \mathrm{O}_{5}$

B.R. Jooste, H.J. Viljoen

(University of Nebraska-Lincoln)

In 1985 it was first reported that monoclinic $\mathrm{Ta}_{2} \mathrm{O}_{5}$ has piezoelectric properties comparable to $\mathrm{ZnO}$. In this work we report on the deposition, characterization and qualitative assessment of the piezoelectric behavior of orthorhombic $\mathrm{Ta}_{2} \mathrm{O}_{5}$. Reactive magnetron sputtering was used to deposit thin films of $\mathrm{Ta}_{2} \mathrm{O}_{5}$ onto substrates of $316 \mathrm{~L}$ stainless steel. Without substrate heating the crystallinity was poor. A rapid thermal anneal improved the crystallinity. The orthorhombic phase was dominantly present on all substrates. The piezoelectric property was qualitatively assessed, including a high temperature test at $650^{\circ} \mathrm{C}$.

Order No.: JA802-031

(C) 1997 MRS

Practical aspects in the drawing of an optical fiber

S.R. Choudhury, Y. Jaluria

(Rutgers University)

The transport processes in the furnace for the continuous drawing of optical fibers have been studied numerically and analytically. Practical circumstances and operating conditions are considered. A peripheral gas flow configuration has been modeled, along with irises at the ends, as employed in practical furnaces. The neck-down profile of the fiber is not chosen, but has been generated on the basis of a surface force balance. The results obtained are validated by comparisons with earlier experimental results. A detailed analysis has been carried out to determine the relative contributions of different forces during the drawing process. Even though the internal viscous stress is shown to be the major contributor to the draw tension, it is found that under certain operating conditions, the force due to gravity is significant, especially at the beginning of the neck-down region. For a peripheral flow configuration, the effect of flow entrance is found to be very important in determining the necking shape. However, the effect of the iris size on the fiber temperature field is found to be negligible. It is found that for a given furnace temperature and fiber radius, there is an upper limit for draw-down speed at which a fiber can be drawn without rupture. Practical ranges of draw speeds and furnace temperature conditions are identified for the process to be feasible.

Order No.: JA802-032

(C) 1997 MRS

Thermal transport due to material and gas flow in a furnace for drawing an optical fiber

S.R. Choudhury, Y. Jaluria

(Rutgers University)

The transport processes involved in the neck-down region for optical fiber drawing are numerically investigated. In this manufacturing process, a moving glass rod is heated in a furnace containing an inert gas environment and drawn into a thin optical fiber. The conjugate problem is solved considering both radiation and convection, with focus on the latter. Two different flow configurations, involving inert gas flow in the same as well as in the opposite direction as the moving preform/fiber, are considered in this study. A coordinate transformation is used to change the complicated computational domains in the gas and the fiber to rectangular ones. The transport in the fiber is coupled with that in the gas through the boundary conditions. The radiative thermal transport is calculated using an enclosure model developed in an earlier study. The numerical results on convective flow and transport are validated by comparing with results available in the literature for simpler configurations. The effects of several important parameters such as fiber draw speed, inert gas velocity, furnace dimensions and gas properties on the flow and temperature distributions 
are investigated. For the aiding flow case, in which the inert gases flow in the same direction as the fiber, heat transfer to the fiber increases as the gas velocity increases. For opposing flow, a recirculating region appears in the gas, close to the moving fiber surface, causing reduction in heat transfer as compared to the aiding case. The thickness of this recirculating zone decreases with increasing inert gas velocity. Radiation is found to be the dominant mode of heat transfer in the overall heating of the preform/fiber, with nitrogen as the inert gas. However, near the edges of the furnace, radiation heat transfer is relatively small and convection becomes very important. Also, the convective transfer rate is relatively large near the flow entrance because of the large temperature difference between the gas and the fiber. However, away from the entrance, the gas heats up and the temperature difference relative to the fiber decreases, resulting in a smaller convective heat transfer rate. The relevance of the results to various aspects of the fiber drawing process is discussed.

Order No.: JA802-033

(C) 1997 MRS

Crystallization of ternary $\mathrm{Zr}$ based glasses-Kinetics and microstructure G.K. Dey, R.T. Savalia, E.G. Baburaj, S. Banerjee (Bhabha Atomic Research Centre)

The effect of ternary addition on the thermal stability and the sequence and the kinetics of crystallization of metallic glasses $\mathrm{Zr}_{76}$ $\left.\mathrm{Fe}_{(24-x}\right) \mathrm{Ni}_{x}(\mathrm{x}=0,4,8,12,16,20,24)$ have been examined. It has been found that the surface crystallization occurs in the composition range $16<x<20$, leading to the formation of an ordered $\mathrm{Fe}$-rich $(\mathrm{Fe}, \mathrm{Ni})_{3} \mathrm{Zr}$ cubic phase, followed by the transformation of the bulk to a mixture of $\alpha-\mathrm{Zr}$ and $\mathrm{Zr}_{2} \mathrm{Ni}$.
Crystallization of alloys containing 12 to $20 \%$ Fe occurs at lower temperatures by primary crystallization of $\mathrm{Zr}_{3}(\mathrm{Fe}, \mathrm{Ni})$, followed by decomposition of the remaining amorphous matrix by eutectic crystallization giving rise to $\alpha-Z r+Z r_{2} N i$. At higher temperatures these alloys transform polymorphically to $\mathrm{Zr}_{3}(\mathrm{Fe}, \mathrm{Ni})$ in which Ni partially substitutes $\mathrm{Fe}$ in the $\mathrm{Zr}_{3} \mathrm{Fe}$ lattice. Copious nucleation of $\mathrm{Zr}_{3}(\mathrm{Fe}, \mathrm{Ni})$ phase in these alloys, leading to the formation of a nanophase structure has been observed. This is consistent with the prediction of increasing nucleation rate for Fe-rich compositions. The crystal nucleation and growth kinetics have been examined for primary, eutectic and polymorphic crystallization processes. The observed nucleation and growth behaviors have been rationalized by considering the role of the quenched in nuclei and the activation energies of nucleation and growth.

Order No.: JA802-034

(C) 1997 MRS

\section{ERRATUM}

Erratum: "In situ $x$-ray Investigation of hydrogen charging in thin film bimetallic electrodes" [J. Mater. Res. 8, 2091 (1997)]

N.M. Jisrawi, H. Wiesmann, M.W. Ruckman, T.R. Thurston, G. Reisfeld, B.M. Ocko, M. Strongin

(Brookhaven National Laboratory)

After this article appeared in the August 1997 issue of Journal of Materials Research, the authors noticed that the abscissa of Figure 3(a) was incorrectly labeled. Below is the correct version.

Order No.: JA802-035

(C) 1997 MRS

Please use the convenient postcard located in the back of the MRS Bulletin to order JMR reprints. When ordering single article reprints please note they are not available until the issue is published. See JMR Abstracts on the MRS Website at http://www.mrs.org/publications/jmr/jmra/.

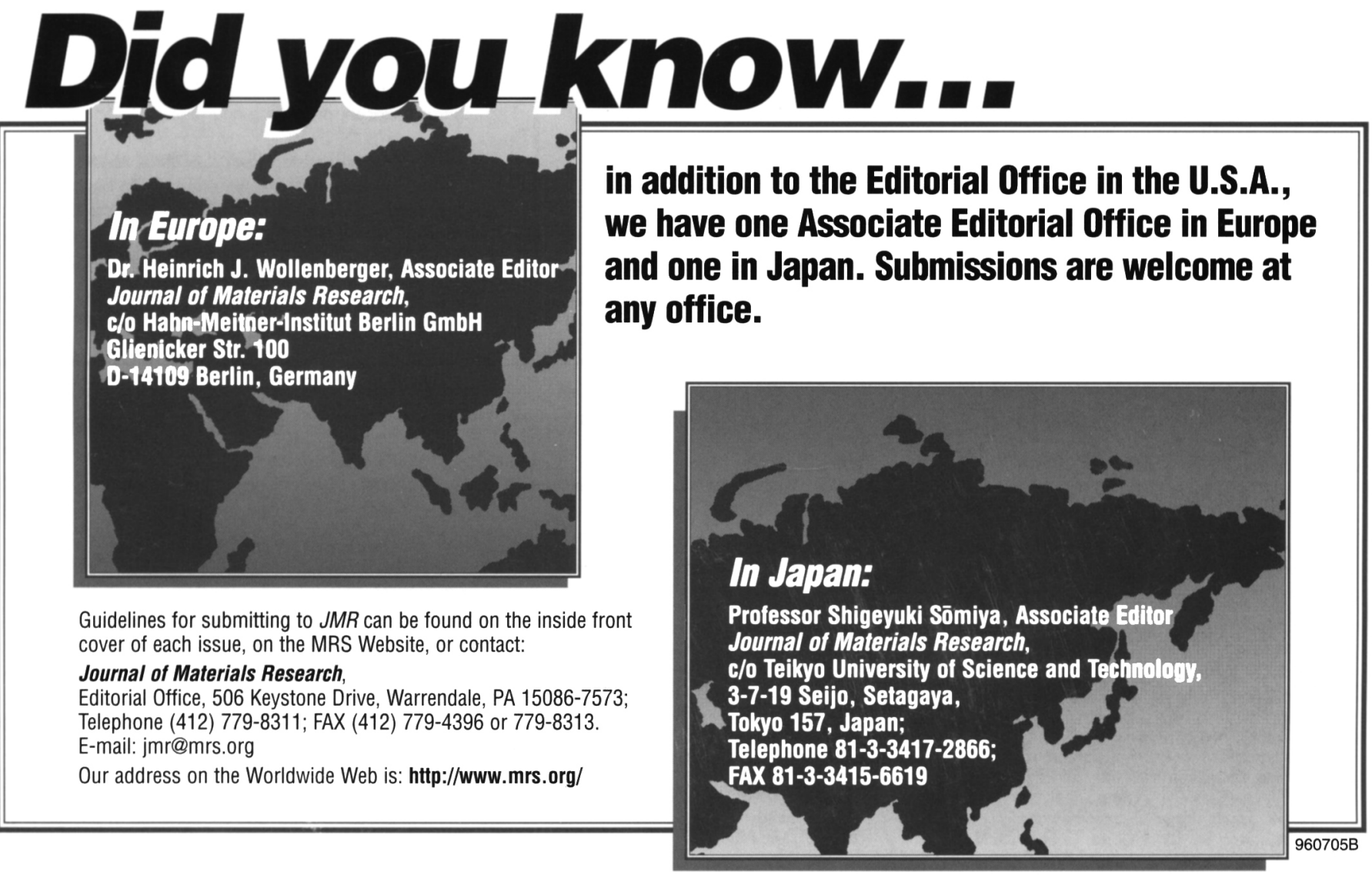




\section{Encounter Excellence...Advertise With MRS!}

The materials research community represents one of the most lively markets for emerging technology. The Materials Research Society offers three advertising venues that penetrate the market, delivering your message to a powerful mix of

decision-makers from all segments of the international materials research community.

\section{MRS Advertising Rates}

\begin{tabular}{|c|c|c|c|}
\hline Ad Size & $\begin{array}{r}\text { MRS } \\
\text { Bulletin }\end{array}$ & $\begin{array}{l}\text { Journal of } \\
\text { Materials } \\
\text { Research }\end{array}$ & $\begin{array}{r}\text { MRS } \\
\text { Membership } \\
\text { Directory }\end{array}$ \\
\hline 2 page spread & $\$ 2,650$ & $\$ 2,220$ & $\$ 3,415$ \\
\hline Full page & $\$ 1,535$ & $\$ 1,215$ & $\$ 1,850$ \\
\hline $2 / 3 \mathrm{pg}$ & $\$ 1,295$ & $\$ 975$ & $\$ 1,435$ \\
\hline $1 / 2 \mathrm{pg}$. island & $\$ 1,220$ & N/A & $\$ 1,195$ \\
\hline 1/2 pg. vertical & $\$ 1,135$ & $\$ 965$ & $\$ 1,180$ \\
\hline $1 / 2 \mathrm{pg}$. horizontal & $\$ 1,130$ & $\$ 935$ & $\$ 1,135$ \\
\hline $1 / 3 \mathrm{pg}$. island & $\$ 995$ & $\mathrm{~N} / \mathrm{A}$ & $\$ 1,020$ \\
\hline $1 / 3 \mathrm{pg}$ & $\$ 950$ & $\$ 795$ & N/A \\
\hline $1 / 4 \mathrm{pg}$ & $\$ 835$ & N/A & N/A \\
\hline $1 / 4$ pg. island & $\$ 820$ & N/A & N/A \\
\hline $1 / 6 \mathrm{pg}$ & $\$ 745$ & N/A & N/A \\
\hline Four-color process, add & $\$ 998$ & $\$ 998$ & $\$ 998$ \\
\hline Metallic 2-color, add & $\$ 598$ & $\$ 598$ & $\$ 598$ \\
\hline Matched 2-color, add & $\$ 538$ & $\$ 538$ & $\$ 538$ \\
\hline Standard 2-color, add & $\$ 498$ & $\$ 498$ & $\$ 498$ \\
\hline \multicolumn{4}{|c|}{$N / A=$ Size not available } \\
\hline \multicolumn{4}{|c|}{$\begin{array}{l}\text { Rates are for a one-time insertion only. Multiple-time insertion rates } \\
\text { available upon request. Match prints are required with color ads. }\end{array}$} \\
\hline
\end{tabular}

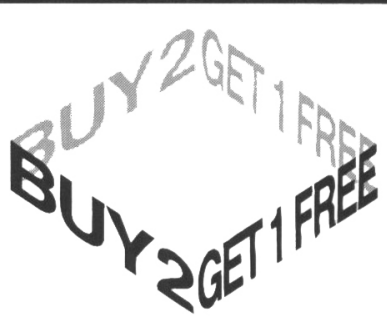

\section{Triple Your Return}

Reach materials scientists 3 different ways and SAVE MONEY at the same time. Purchase an ad in Journal of Materials Research and the annual 1998 MRS Membership Directory and receive a FREE AD in MRS Bulletin.

Offer expires June 30, 1998.

Contact Mary E. Kaufold, Materials Research Society at 412-779-8312 to place your ads.

\section{Journal of Materials Research}

The archival front-runner in advanced materials, Journal of Materials Research contains archival papers, commentaries and reviews, and communications. Published monthly, JMR is comprehensive in nature, and over the past 13 years has addressed more than 150 different topics on materials characterization, processing and synthesis.

$J M R$ provides a consistent level of editorial contributions from leaders in the materials research community. So you can count on consistent readership and frequent exposures for your advertising message. In addition, $J M R^{\prime}$ s archival nature extends the length of that exposure, maximizing the impact of your sales and marketing strategies.

\section{MRS Bulletin}

One of the most widely recognized and highly respected publications in materials science research, MRS Bulletin is published monthly and delivers news, breakthroughs and reviews from an interdisciplinary perspective. Spanning a wide range of leading-edge materials developments, topical overviews include:

January 1998

Theme: Technical Articles/Special Features Advertising Closing: December 1, 1997

February 1998

Theme: Quantum Dots

Guest Editor: Alex Zunger, National Renewable Energy Laboratory Preview: 1998 MRS Spring Meeting \& Exhibit Advertising Closing: January 2, 1998

March 1998

Theme: Materials for Sports

Guest Editor: F.H. Froes, University of Idaho Bonus Distribution:

1998 MRS Spring Meeting and Exhibit and Society of Vacuum Coaters Conference Advertising Closing: February 2, 1998

April 1998

Theme: Silicon-Based Optoelectronics

Guest Editor: Salvatore Coffa, CNR-IMETEM

Advertising Closing: March 2, 1998
May 1998

Theme: Technical Articles/Special Features

Advertising Closing: April 1, 1998

June 1998

Theme: Fundamentals of Friction

Guest Editor: Jacqueline Krim, Northeastern

University

Advertising Closing: May 1, 1998

July 1998

Theme: Emergence of Ternary Chalcopyrites as Nonlinear Optical Materials

Guest Editors: Ravi Pandey, Michigan Tech University and Melvin C. Ohmer, AFOSR-Wright Laboratory

Advertising Closing: June 1, 1998

August 1998

Theme: Materials Science of Field Responsive Smart Fluids

Guest Editor: Pradeep P. Phulé, University of Pittsburgh

Advertising Closing: July 1, 1998
September 1998

Theme: Diamond Films: Recent Developments

Guest Editors: Dieter M. Gruen, Argonne National Laboratory and lan Buckley-Golder, Harwell Laboratory, United Kingdom

Advertising Closing: August 3, 1998

October 1998

Theme: Colloidal Materials

Guest Editor: David G. Grier, University of Chicago

Preview: 1998 MRS Fall Meeting \& Exhibit

Advertising Closing: September 1, 1998

November 1998

Bonus Distribution: 1998 MRS Fall Meeting \& Exhibit

Advertising Closing: October 1, 1998

December 1998

Advertising Closing: November 2, 1998 